\title{
Is ventricular arrhythmia in repaired tetralogy of Fallot an effect of operation or a consequence of the course of the disease?
} $A$ prospective study

\author{
IAN D SULLIVAN,* PATRICIA PRESBITERO,† VANDA M GOOCH, * \\ ERIO ARUTA, $\dagger$ JOHN E DEANFIELD* \\ From the ${ }^{\star}$ Thoracic Unit, The Hospital for Sick Children, Great Ormond Street, London and $†$ San Giovanni \\ Hospital, Turin, Italy
}

SUMMARY Ventricular arrhythmia is common after repair of tetralogy of Fallot. Such arrhythmia could be caused by damage at surgical repair or it could be part of the course of the disease. Fifty patients, 32 aged 1-7 years and 18 aged 13-43 years at surgical repair, underwent 24 hour electrocardiographic monitoring before and 2-75 (mean 44) months after repair. Before operation none of the younger group had appreciable ventricular arrhythmia, whereas ventricular arrhythmia was already present in eight $(45 \%)$ of 18 patients in the older group. At follow up ventricular arrhythmia was present in four patients from the younger group and seven from the older group. Three of these four younger patients had had insertion of a conduit from the right ventricle to the pulmonary artery or reoperation. Six of the seven older patients had had appreciable ventricular arrhythmia before operation. New ventricular arrhythmia developed in only two (5\%) of the 43 patients who had uncomplicated repair of tetralogy of Fallot.

Thus the high frequency of ventricular arrhythmia after repair of tetralogy of Fallot cannot be attributed to the effect of operation alone because in the majority of patients it was already present before operation. Preoperative ventricular arrhythmia occurred almost exclusively in older patients; this suggests that early surgery may reduce the occurrence of this late complication.

Ventricular arrhythmia is well recognised after repair of tetralogy of Fallot and has been suggested as a cause of late sudden death. ${ }^{12}$ Factors which predispose to the high incidence of ventricular arrhythmia in patients after operation remain controversial. Residual haemodynamic abnormalities after surgery, such as right ventricular systolic and diastolic hypertension, ${ }^{3}$ increased right ventricular dimension, ${ }^{4}$ and diminished right ventricular ejection fraction, ${ }^{5}$ have been regarded as important. In a previous study, however, the frequency of ventricular arrhythmia was already high in older patients

Requests for reprints to Dr John E Deanfield, The Hospital for Sick Children, Great Ormond Street, London WC1N 3JH.

Accepted for publication 8 January 1987 before repair of tetralogy of Fallot. ${ }^{6}$ This has implications for strategies aimed at reducing the occurrence of this late complication.

We have therefore performed a prospective study to determine the relative important of preoperative, operative, and postoperative factors in the genesis of ventricular arrhythmia. This aimed to test the hypothesis that the presence of ventricular arrhythmia after surgical repair of tetralogy of Fallot depends as much on the natural cause of the disease and preoperative status as on the direct effect of the operation itself.

\section{Patients and methods}

PATIENTS

We studied 55 consecutive patients undergoing surgery for classic tetralogy of Fallot. There were 
two groups. Group A consisted of 35 children, aged $1 \cdot 2-7 \cdot 7$ (median $4 \cdot 3$ ) years at repair, admitted to the Hospital for Sick Children, London. Group B consisted of 20 older patients, aged 13-43 (median 28) years, who underwent repair of tetralogy of Fallot in Turin.

Previous palliative surgery had been performed in 20 patients from group $A$ and in 17 patients from group B (Blalock-Taussig shunt 29, Potts shunt 3, Waterston shunt 1, Brock procedure 4). Repair involved right ventriculotomy in all patients except for one in group B whose repair was performed through the tricuspid and pulmonary valves. The right ventricular outflow tract procedure consisted of an infundibulectomy, usually together with an outflow tract or transannular patch, except for three patients in group A who required right ventricle to pulmonary artery conduits because of an aberrant coronary artery. Reoperation was necessary in four patients, all from group A, for closure of residual ventricular septal defect or pulmonary valve replacement or both.

All patients underwent 24 hour electrocardiographic monitoring before repair. There were three operative deaths in group A. Follow up electrocardiographic monitoring was performed in all 32 remaining patients 8-75 (median 54) months after repair. There were no operative deaths in group B and follow up electrocardiographic monitoring was performed 2-42 (median 30) months after repair in all except two patients who were symptom free and declined investigation. There were no late cardiac deaths; the only death occurred in a previously symptom free group B patient after postpartum haemorrhage.

\section{ELECTROCARDIOGRAPHIC MONITORING}

Electrocardiographic monitoring was performed with Oxford Medilog or Avionics cassette recorders with bipolar CM1 and CM5 leads. The tapes were analysed with an Oxford Medilog or Avionics high speed analyser. A modification of Lown criteria, ${ }^{7}$ based on frequency and complexity of ventricular arrhythmia, was used for all the recordings: grade 0 $=$ no ventricular extrasystoles; grade $\mathrm{I}=$ ventricular extrasystoles with peak hourly rate $<30$; grade II $=>30$ uniform ventricular extrasystoles in any hour; grade III = couplets (two consecutive ventricular extrasystoles), or multiform ventricular extrasystoles with peak hourly : rate $>30$; grade IV = ventricular tachycardia (three or more consecutive extrasystoles with mean rate $>110$ beats/min).

Standard 12 lead electrocardiograms were used to assess the mean frontal plane QRS axis and intraventricular conduction abnormality.
STATISTICAL ANALYSIS

The incidence of ventricular arrhythmia (grade II or greater) between groups A and B and within groups, before and after surgery, was compared by Fisher's exact test. Differences were regarded as significant if the probability of a chance occurrence was $<0.05$.

\section{Results}

\section{PREOPERATIVE ELECTROCARDIOGRAPHIC} MONITORING

Before surgical repair none of the younger patients (group A) had appreciable ventricular arrhythmia (grade II or greater). All except three had uninterrupted sinus rhythm, and the remainder had a total of $<10$ uniform ventricular extrasystoles during the 24 hour period. In contrast, eight $(45 \%)$ of the 18 older patients (group B) already had ventricular arrhythmia of grade II or greater during preoperative ambulatory monitoring; this was a significantly higher incidence than in the younger patients of group $A(p=0.0009)$. These included five $(28 \%)$ patients with frequent complex ventricular arrhythmia (grade III) (fig 1).

\section{FOLLOW UP ELECTROCARDIOGRAPHIC}

\section{MONITORING}

At follow up after repair four $(13 \%)$ of the 32 patients in group A had ventricular arrhythmia of grade II or greater (fig 2). The occurrence of new ventricular arrhythmia in the subgroup of seven patients with conduit insertion or repeat surgery was significantly higher than in the patients who had

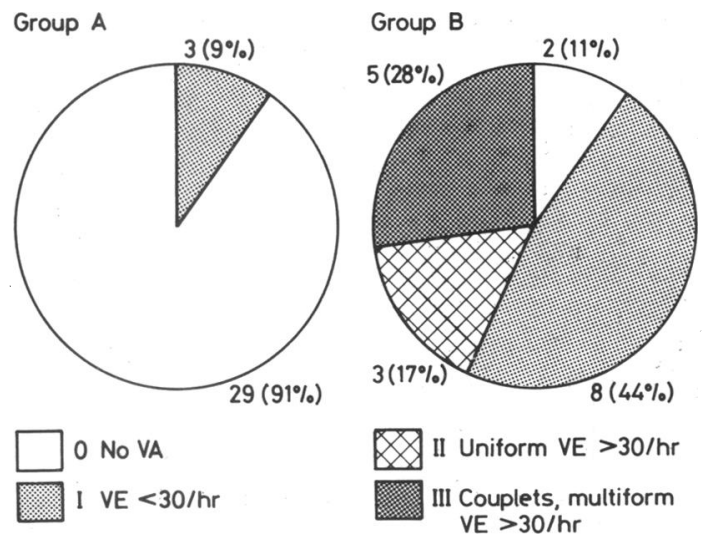

Fig 1 Preoperative ventricular arrhythmia on electrocardiographic monitoring in the two groups of patients. In group $A$ (younger patients at repair) the frequency and grade of ventricular arrhythmia were low. In contrast $45 \%$ of group $B$ (older patients at repair) had frequent or complex ventricular arrhythmia. VA, ventricular arrhythmia; VE, ventricular extrasystole. 


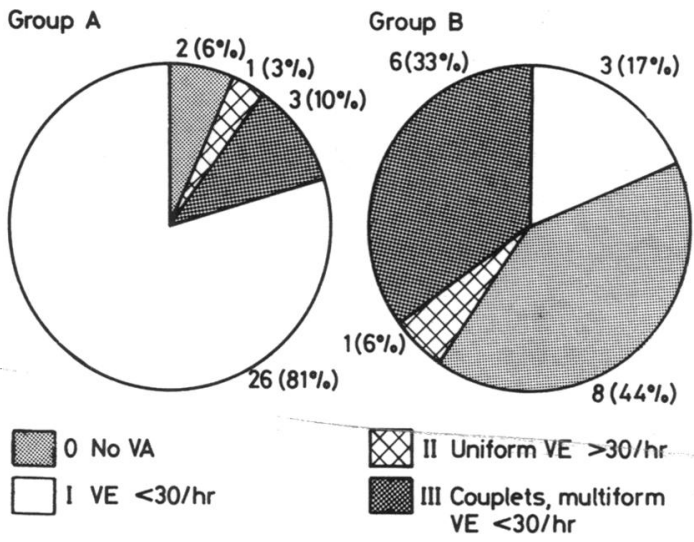

Fig 2 Ventricular arrhythmia on follow up electrocardiographic monitoring. The frequency of ventricular arrhythmia in group $A$ patients remained low while the high incidence of ventricular arrhythmia in group $B$ patients noted before operations persisted. See legend to fig 1 for abbreviations.

uncomplicated repair ( $3 / 7$ vs $1 / 25, p=0.02)$ (table).

At follow up evaluation seven $(39 \%)$ of the 18 older patients (group B) had ventricular arrhythmia of grade II or greater (fig 2). Ventricular arrhythmia of a similar grade had been present in six of these during preoperative monitoring. Thus only one patient developed ventricular arrhythmia of grade II or greater that had not been detected before surgery (fig 3). Because most ventricular arrhythmia was present before operation, there was no relation between postoperative ventricular arrhythmia and the type of surgery in this older group, unlike group A. No patient had ventricular tachycardia.

Right bundle branch block was present in 45 $(90 \%)$ of the 50 patients after surgery, with additional left axis deviation (frontal plane QRS axis $\left.>-30^{\circ}\right)$ in five $(10 \%)$. There was no relation between ventricular arrhythmia detected by electrocardiographic monitoring and these conduction defects on the 12 lead electrocardiogram.

Table Relation of surgical procedures and postoperative ventricular arrhythmia in group $A$ (younger patients at repair).

$\left.\begin{array}{lrll}\hline & \text { No } & \multicolumn{2}{c}{\text { Ventricular arrhythmia }} \\
\hline \text { Simple repair } & 25 & 1 & (4 \%) \\
\text { RV PA conduit } & 3 & 1 \\
\text { Reoperation: } & 4 & 2\end{array}\right\} \quad$\begin{tabular}{l}
$(43 \%)$ \\
$\begin{array}{c}\text { (VSD, VSD + PVR, PVR) } \\
\text { Total }\end{array}$ \\
\hline
\end{tabular}

PA, pulmonary artery; PVR, pulmonary valve replacement; $R V$, right ventricle; VSD, ventricular septal defect.
Sullivan, Presbitero, Gooch, Aruta, Deanfield

\begin{tabular}{|c|c|c|}
\hline $\begin{array}{l}\text { Grade of } \\
\text { YA }\end{array}$ & Before & After \\
\hline $0-1$ & 10 & 11 \\
\hline 2 & 3 & 1 \\
\hline 3 & 5 & 6 \\
\hline 4 & 0 & 0 \\
\hline
\end{tabular}

Fig 3 Comparison of grade of ventricular arrhythmia $(V A)$ in group $B$ before and after operation. Only one patient had appreciable ventricular arrhythmia after repair that had not been noted on preoperative monitoring. See figs 1 and 2 for ventricular arrhythmia grading.

The overall occurrence of postoperative ventricular arrhythmia for groups $A$ and $B$ together was $22 \%$ $(11 / 50)$. Of these, only two patients had new ventricular arrhythmia after uncomplicated surgical repair. The remainder had either insertion of a conduit from the right ventricle to the pulmonary artery (one patient), reoperation (two patients), or had similar ventricular arrhythmia already present before operation.

\section{Discussion}

Despite the fact that ventricular arrhythmia is widely recognised after repair of tetralogy of Fallot, neither the important precipitating factors nor specific indications for arrhythmia suppression have been adequately defined.

Some groups have reported an association between the presence of ventricular arrhythmia and inadequate repair of tetralogy of Fallot. Garson et al noted that about $25 \%$ of patients with right ventricular systolic pressure $>60 \mathrm{~mm} \mathrm{Hg}$ demonstrated postoperative ventricular arrhythmia, compared with $8 \%$ of those with a right ventricular systolic pressure $<40 \mathrm{~mm} \mathrm{Hg} .^{3}$ Webb Kavey et al failed to demonstrate a similar haemodynamic correlation despite finding ventricular arrhythmia in $42 \%$ of 72 patients. ${ }^{8}$ In the group of patients with ventricular arrhythmia, however, they found a more subtle haemodynamic impairment on radionuclide and cross sectional echocardiographic examination. ${ }^{9}$

These retrospective studies, however, included many older patients operated on in the early years of cardiopulmonary bypass, and they did not measure the occurrence of ventricular arrhythmia before surgical repair. In the only previous study to do so, half the 24 patients aged $\geqslant 8$ years had ventricular arrhythmia before repair-similar to those found in postoperative recordings. ${ }^{6}$ This suggested that the 
natural course of the disease and the preoperative state of the right ventricle might be at least as important as the direct effect of operation on the genesis of postoperative ventricular arrhythmia. Our prospective study supports this hypothesis; most of our patients with ventricular arrhythmia after repair of tetralogy of Fallot had this abnormality before operation. Only two $(5 \%)$ of the 43 patients with uncomplicated repair developed new ventricular arrhythmia after operation.

Why does ventricular arrhythmia occur in patients with tetralogy of Fallot, even before repair? The likelihood of its developing appears to increase with age. This is supported by both the relation between older age at repair and symptoms of arrhythmia ${ }^{10}$ and by the results of electrocardiographic monitoring. ${ }^{6}$ The anatomical substrate for this may be the degree of right ventricular myocardial fibrosis. In older patients undergoing repair for tetralogy of Fallot pathological studies have demonstrated extensive right ventricular fibrosis which is not present in younger children. ${ }^{1112}$ Similar right ventricular fibrosis was noted at necropsy in patients who died suddenly late after repair of tetralogy of Fallot. ${ }^{13}$ Electrophysiological studies with endocardial mapping have demonstrated fractionated depolarisation at multiple sites in the right ventricle in patients after repair of tetralogy of Fallot that correlated with ventricular arrhythmia on electrocardiographic monitoring. This suggests a widespread abnormality of right ventricular electrical activity rather than a central conduction defect specifically related to a direct effect of surgical repair. ${ }^{14}$

Surgical repair clearly may have an effect in predisposing to ventricular arrhythmia. Sustained ventricular tachycardia has been mapped to the site of incision in the right ventricular outflow tract ${ }^{15}$ and fractionated depolarisation has been recorded from the ventricular septum ${ }^{16}$-presumably this is related to repair of the ventricular septal defect. In our study there were five patients who did not have ventricular arrhythmia before operation but who had appreciable ventricular arrhythmia at follow up. It is notable, however, that most of them had extensive or repeated surgery likely to produce more right ventricular scarring than straightforward repair of tetralogy of Fallot.

The two groups in this study were managed at different institutions. Because we were investigating intrapatient differences, however, this does not compromise our conclusions. Furthermore, our results indicate that the operation itself had little direct effect.

As this is a prospective study, follow up is necessarily shorter than in previous retrospective studies.
It could be argued that with time ventricular arrhythmia will develop even in patients operated on at a younger age. Indeed, Garson et al consider that patients with early repair "have not lived long enough to develop premature ventricular complexes." They believe that this explains the relation they found between the occurrence of postoperative ventricular extrasystoles and older age at repair. ${ }^{3}$ Nevertheless, from our previous analysis of 85 patients we could find no significant relation between ventricular arrhythmia and duration of follow up ${ }^{6}$ when this was analysed independently of age of surgical repair. This question will need to be examined in prospective studies, such as this one, with a longer follow up.

We did not attempt to define the indications for antiarrhythmic treatment in patients with ventricular arrhythmia after repair of tetralogy of Fallot, which remain controversial. There have been no late cardiac deaths among this study group to date and most patients are symptom free. In a separate six year prospective study the prognostic significance of asymptomatic ventricular arrhythmia has been low. ${ }^{17}$

This study highlights the importance of the natural course of ventricular arrhythmia in tetralogy of Fallot. Preoperative abnormalities of the right ventricular myocardium at operation seem to be as important as any direct effect of operation in predisposing to subsequent ventricular arrhythmia. Preoperative ventricular arrhythmia occurred exclusively in the older patients. It is thus tempting to speculate that earlier surgical repair, which has become standard, may reduce the occurrence of this late complication.

\section{References}

1 Deanfield JE, McKenna WJ, Hallidie-Smith KA. Detection of late arrhythmia and conduction disturbance after correction of tetralogy of Fallot. $\mathrm{Br}$ Heart $\mathcal{F}$ 1980;44:248-53.

2 Gillette PC, Yeoman MA, Mullins CE, McNamara DG. Sudden death after repair of tetralogy of Fallot. Electrocardiographic and electrophysiologic abnormalities. Circulation 1977;56:566-71.

3 Garson A Jr, Randall DC, Gillette PC, et al. Prevention of sudden death after repair of tetralogy of Fallot: treatment of ventricular arrhythmias. $\mathcal{F} \mathrm{Am}$ Coll Cardiol 1985;6:221-7.

4 Rosing DR, Borer JS, Kent KM, et al. Long-term hemodynamic and electrocardiographic assessment following operative repair of tetralogy of Fallot. Circulation 1978;58(suppl I):209-17.

5 Kobayashi J, Hirose $H$, Nakano S, Matsuda $H$, Shirakura R, Kawashima Y. Ambulatory electrocardiographic study of the frequency and cause of ventricular arrhythmia after correction of tetralogy of 
Fallot. Am $\mathcal{f}$ Cardiol 1984;54:1310-3.

6 Deanfield JE, McKenna WJ, Presbitero P, England D, Graham GR, Hallidie-Smith K. Ventricular arrhythmia in unrepaired and repaired tetralogy of Fallot. Relation to age, timing of repair, and haemodynamic status. Br Heart $\mathcal{F} 1984 ; 52: 77-81$.

7 Ryan M, Lown B, Horn H. Comparison of ventricular ectopic activity during 24-hour monitoring and exercise testing in patients with coronary heart disease. $N$ Engl f Med 1975;292:224-9.

8 Webb Kavey R-E, Blackman MS, Sondheimer HM. Incidence and severity of chronic ventricular dysrhythmias after repair of tetralogy of Fallot. $\mathrm{Am}$ Heart ₹ 1982;103:342-50.

9 Webb Kavey R-E, Thomas FD, Byrum CJ, Blackman MS, Sondheimer HM, Bove EL. Ventricular arrhythmia and biventricular dysfunction after repair of tetralogy of Fallot. $\mathcal{F} \mathrm{Am}$ Coll Cardiol 1984; 4:126-31.

10 Katz NM, Blackstone EH, Kirklin JW, Pacifico AD, Bargeron LM Jr. Late survival and symptoms of repair of tetralogy of Fallot. Circulation 1982; 65:403-10.

11 Jones M, Ferrans VJ. Myocardial degeneration in congenital heart disease. Comparison of morphologic findings in young and old patients with congenital heart disease associated with muscular obstruction to right ventricular outflow. Am $\mathcal{F}$ Cardiol 1977; 39:1051-63.
12 Meurs-van Woezik H, Brink HS, Essed CE, Debets T, Klein HW, Krediet P. Myocardial fibrosis in tetralogy of Fallot [Abstract]. In: Doyle EF, Engle MA, Gersony WM, Rashkind WJ, Talner NS, eds. Second world congress of pediatric cardiology. New York: Springer-Verlag, 1985:145.

13 Deanfield JE, Ho S-Y, Anderson RH, McKenna WJ, Allwork SP, Hallidie-Smith KA. Late sudden death after repair of tetralogy of Fallot: a clinico-pathologic study. Circulation 1983;67:626-31.

14 Deanfield J, McKenna W, Rowland E. Local abnormalities of right ventricular depolarization after repair of tetralogy of Fallot: a basis for ventricular arrhythmia. Am J Cardiol 1985;55:522-5.

15 Horowitz LN, Vetter VL, Harken AH, Josephson ME. Electrophysiologic characteristics of sustained ventricular tachycardia occurring after repair of tetralogy of Fallot. Am J Cardiol 1980;46:446-52.

16 Kugler JD, Pinsky WW, Cheatham JP, Hofschire PJ, Morring PK, Fleming WH. Sustained ventricular tachycardia after repair of tetralogy of Fallot: electrophysiologic findings. Am J Cardiol 1983;51:1137-43.

17 Deanfield J, Franklin R, McKenna WJ, Dickie S, Gersony W, Hallidie-Smith K. Prognostic significance of ventricular arrhythmia after repair of tetralogy of Fallot: a prospective study. In: Doyle EF, Engle MA, Gersony WM, Rashkind WJ, Talner NS, eds. Pediatric cardiology. New York: Springer-Verlag, 1986: 467-8. 